\title{
Urethral Leiomyoma: A Benign Smooth Muscle Tumor in Female Urethra
}

Binyamin Butt ${ }^{1}$, Nazli Hameed ${ }^{2}$

Obstetrics and Gynecology Department, Shalamar Medical and Dental College, Lahore ${ }^{1,2}$

\begin{abstract}
Background: A benign smooth muscle fibroid was found in urethra. The tumor can be seen in females of reproductive age group with a peak incidence reported at 41 years. The rarity is supported by less than a hundred cases reported in literature.

Case presentation: In this case report a 48 year old woman presented to us with incontinence and poor urinary stream and was found to have a urethral leiomyoma. The lesion was enucleated and dead space closed. Patient made a smooth postoperative recovery.

Conclusion: Urethral leiomyoma is a rare benign tumor affecting females of reproductive years of life. The clinical diagnosis can be aided by endoscopic or radiological investigations. Surgical excision is the preferred treatment with a low risk of recurrence.
\end{abstract}

Keywords: Leiomyoma, Urethra

\section{INTRODUCTION}

Leiomyoma arises from normal smooth muscle content in the urethra. ${ }^{1}$ Though it may be seen at any time during the reproductive years of life, the peak incidence is seen at 41 years of age. ${ }^{2}$ The first reported case was in 1894 by Butnerand the total number of reported cases is less than a hundred. ${ }^{3}$ Urethral leiomyoma arises from deep smooth muscle cells of mesenchymal origin and follow a benign course. ${ }^{4}$ The presentation can be variable including recurrent urinary tract infections $(64.3 \%)$, dysuria, pressure symptoms, difficulty in voiding eventually leading to urinary obstruction. The risk of malignant transformation is not yet reported. ${ }^{5}$

\section{Corresponding Author:}

Prof. Dr. Nazli Hameed

Gynecology and Obstetrics Department

Shalamar Medical and Dental College, Lahore

Email address: Nazlihameed1@gmail.com

Received 03.05.2019, Revised 18.06.2019, Accepted 25.06.2019

\section{CASE REPORT}

A 48 year old woman presented with itching and heaviness in vagina for 6 months and urinary voiding disturbance for 2 months. There is no significant past medical history. She is para 4 and had 2 previous cesarean sections. Physical examination reveals a firm mass of $7 \times 5 \times 3 \mathrm{~cm}$ mass in anterior wall of distal urethra occupying the anterior half of its lumen, light pink in color without sign of inflammation [Figure A]. Tumor was excised on 1-1-19 with repair of ventral wall of urethra [Figure $\mathrm{B} \quad \& \quad \mathrm{C}$. Histopathological report shows multiple fragments largest measuring $4 \times 3 \times 2 \mathrm{~cm}$ and smallest measuring $2 \times 1.5 \times 0.5 \mathrm{~cm}$. Microscopically, nodular piece of tissue covered with benign squamous epithelium the underlying tissue revealed interlacing fascicles of spindle cells, no mitosis, no pleomorphism or necrosis is identified. These features confirm the diagnosis of urethral leiomyoma. Post operatively she recovered well. There has been no recurrence to this date. 


\section{DISCUSSION}

Urethral tumors are quite rare. The lesion has to be carefully examined to differentiate it from ureteroceles, urethral caruncle, diverticulum, prolapse and carcinoma. Other possible diagnoses include Skene's duct cyst and Gartner's duct cyst. ${ }^{6}$ The lesion found in this case arose from deep mesenchymal tissue. It is quite uncommon and a high index of suspicion should be maintained to exclude a complicating leiomyomasarcoma. ${ }^{7}$ The tumor affects women in the reproductive years of life, especially thirties and fortees. ${ }^{7}$ The growth of urethral leiomyoma is hormone dependent as it regresses after menopause. ${ }^{9}$ The tumor is predominantly found in the proximal urethra though distal urethra may also be involved. It commonly arises from the posterior wall of the urethra. Clinical presentation can be variable based on the site and size of the tumor. Presentation can be feeling of a mass, hematuria, urinary retention, incontinence and recurrent urinary tract infection. $8, \quad 9, \quad 10,10$ approximately $23 \%$ patients are asymptomatic and their lesions are picked up and treated incidentally. Like any clinical problem, the importance of a good history and thorough clinical examination cannot be over emphasized. Imaging techniques may be needed on a case to case basis including ultrasound, magnetic resonance imaging (MRI), or computed tomography scan (CT). Transperineal ultrasound also picks up the hypo echoic lesion with whorled appearance; Doppler scan shows compressed peripheral blood supply. ${ }^{11}$ The role of Imaging techniques is to precisely locate the tumor with the extent of tissue infiltration, excluding features suggestive of malignancy. The information is helpful in planning of surgery. ${ }^{12}$ The treatment options are varied as the disease is rare. Use of gonadotropins has been described in the literature. $^{13}$ Local surgical excision is the treatment of choice. ${ }^{14}$ Malignant transformation is not yet reported. The differential diagnosis is represented by urethrocele, a urethral diverticulum, caruncle, and malignancy. The diagnosis is based mainly on a careful clinical examination, while urethroscopy, and radiological imaging can be requested if considered clinically relevant. A histopathological examination is mandatory to exclude malignancy. ${ }^{15}$ The tumor has a has a low rate of recurrence. ${ }^{16}$

\section{CONCLUSION}

Urethral leiomyoma is a rare benign tumor affecting females of reproductive years of life. The clinical diagnosis can be aided by endoscopic or radiological investigations. Surgical excision is the preferred treatment with a low risk of recurrence. Malignant transformation is not yet reported.

Figures: A Written Informed Consent was Taken from the Patient to Include Pictures in the Manuscript.

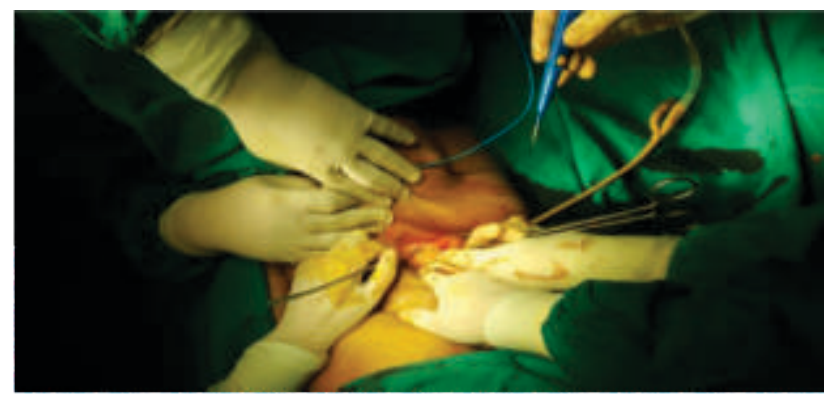

Figure: A

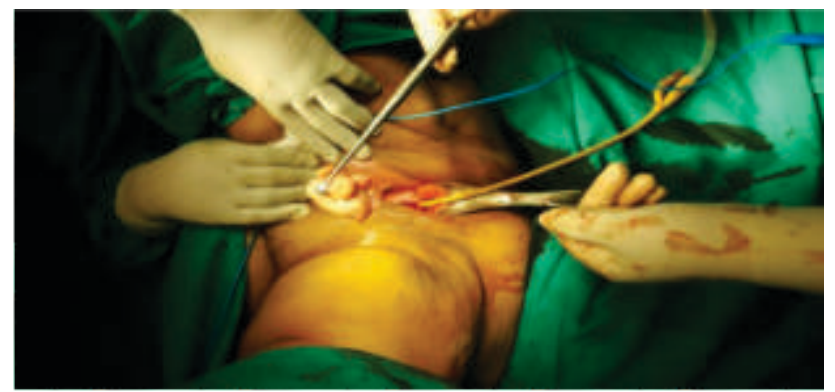

Figure: B

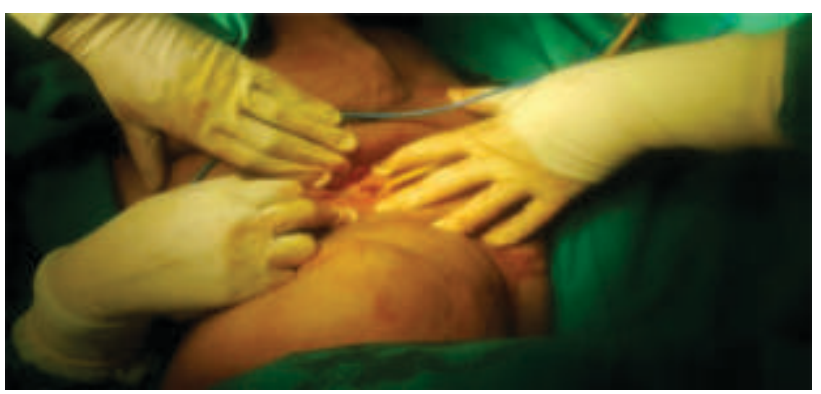

Figure: C 


\section{Conflicts of interest}

The authors had no conflict of interest to disclose.

\section{Contributors}

Initial idea and write up was done by Prof. Nazli

Hameed, editing, proof reading and reference

checking done by Dr. Binyamin Butt

\section{REFERENCES}

1. Rivière $\mathrm{P}$, Bodin R, Bernard G, Deligne E, Peyromaure M, Ponties JE. Leiomyoma of the female urethra. Prog Urol. 2004; 14(6): 11968.

2. Chong KM, Chuang j, Tsai Y L, Hwang JL. A rapidly growing paraurethralmyoma with profuse bleeding from a mucosal vessel: report of a case. Gynecol Obstet Invest. 2006; 61(2): 87-9.

3. Pahwa M, Saifee Y, Pahwa AR, Gupta M. Leiomyoma of the female urethra-a rare tumor: case report and review of the literature. Case Rep Urol. 2012; 2012: 280816

4. Rivière P, Bodin R, Bernard G, Deligne E, Peyromaure M, Ponties JE. Leiomyoma of the female urethra. Prog Urol. 2004; 14: 1196-98.

5. Pahwa M, Saifee Y, Pahwa AR, Gupta M. Leiomyoma of the female urethra - a rare tumor: case report and review of the literature. Case Reports Urol. 2012; 2012: 280816.

6. Blaivas J. G., Flisser A. J., Bleustein C. B., Panagopoulos G. Periurethral masses: etiology and diagnosis in a large series of women. Obstet Gynecol. 2004; 103(5Pt 1)): 842-47.

7. Jalde DD, Godhi SA, Uppin SM, Chako SP, Agrawal AM. A case of urethral leiomyoma a rare presentation. World $\mathrm{J}$ Sci Technol. 2012; 2: 27-28.
8. Migliari R., Buffardi A., Mosso L. Female paraurethral leiomyoma: treatment and longterm follow-up. Int Urogynecol J. 2015; 26(12): 1821-5.

9. Strang A., Lisson S. W., Petrou S. P. Ureteral endometriosis and coexistent urethral leiomyoma in a postmenopausal woman. Int Braz J Urol. 2004; 30(6): 496-8.

10. Pahwa M., Saifee Y., Pahwa A. R., Gupta M. Leiomyoma of the female urethra - a rare tumor: case report and review of the literature. Case Rep Urol. 2012; 2012: 280816.

11. Verma R., Mehra S., Garga U. C., Jain N., Bhardwaj K. Imaging diagnosis of urethral leiomyoma, usual tumour at an unusual location. J Clin Diagn Res. 2014; 8(11): RD04-6.

12. Hubert K. C., Remer E. M., Rackley R. R., Goldman H. B. Clinical and magnetic resonance imaging characteristics of vaginal and paraurethral leiomyomas: can they be diagnosed before surgery? BJU Int. 2010; 105(12): 1686-8.

13. Shen Y.-H., Yang K. Recurrent huge leiomyoma of the urethra in a female patient: a case report. Oncol Lett. 2014; 7(6):1933-35.

14. Elhadari T., Archer R., Barrington J. Urethral leiomyoma: a rare presentation. J Obstet Gynaecol. 2014; 34(2): 208.

15. Merrell R. W., Brown H. E. Recurrent urethral leiomyoma presenting as stress incontinence. Urology. 1981;17(6):588-9.

16. Tantbirojn P., Sansopha L., Thanakit V., Sirisubya N. Paraurethral leiomyoma: a case report. J Med Assoc Thai. 2006; 89(4): 545-9. 